Article

\title{
Suppressing Grain Growth on Cu Foil Using Graphene
}

\author{
Jaeyeong Lee ${ }^{1,2,+}$, Hojun Shin ${ }^{2,+}$, Jae-Young Choi ${ }^{3,4, *}$ and Hak Ki Yu ${ }^{1,2, *}$ \\ 1 Department of Energy Systems Research, Ajou University, Suwon 16499, Korea; smuff20@ajou.ac.kr \\ 2 Department of Materials Science and Engineering, Ajou University, Suwon 16499, Korea; \\ hojun706@ajou.ac.kr \\ 3 School of Advanced Materials Science \& Engineering, Sungkyunkwan University, Suwon 16419, Korea \\ 4 School of Advanced Institute of Nanotechnology (SAINT), Sungkyunkwan University, Suwon 16419, Korea \\ * Correspondence: jy.choi@skku.edu (J.-Y.C.); hakkiyu@ajou.ac.kr (H.K.Y.); Tel.: +82-31-219-1680 (H.K.Y.); \\ Fax: +82-31-219-1613 (H.K.Y.) \\ + These authors contributed equally to this work.
}

Received: 20 August 2018; Accepted: 21 September 2018; Published: 23 September 2018

check for updates

\begin{abstract}
The effect of graphene coating on the growth of grains on bulk copper film was studied. When methane gas is catalytically decomposed on the surface of copper, and a carbon-copper solid solution is formed at high temperature, precipitated carbon on the copper surface forms graphene during rapid cooling through strong $\mathrm{sp}^{2}$ covalent bonding. The graphene layer can prevent the growth of grains by suppressing the diffusion of copper atoms on the surface, even after continuous heat treatment at high temperatures. The actual size of the copper grains was analyzed in terms of repetitive high-temperature heat treatment processes, and the grain growth process was simulated by using thermodynamic data, such as surface migration energy and the binding energy between copper and carbon. In general, transition metals can induce graphene growth on surfaces because they easily form carbon solid solutions at high temperatures. It is expected that the process of graphene growth will be able to suppress grain growth in transition metals used at high temperatures and could be applied to materials that are prone to thermal fatigue issues such as creep.
\end{abstract}

Keywords: graphene; grain growth; $\mathrm{Cu}-\mathrm{C}$ binding energy; pseudo-free-standing

\section{Introduction}

Since the performance of a device (or system) using metal as a component is influenced by grain size [1,2], texture (preferred orientation) [3-5], and surface roughness [6-8], it is necessary to manage these characteristics well, in order to maintain constant device performance. However, because of the nature of metallic materials, these microstructures can be changed by heat from the environment or generated by the device itself (effects on the atomic movement based on Fick's Law) [9-12]. Therefore, a technology that can maintain a constant microstructure for a long time, even at a high temperature, can be said to be very important from the viewpoint of the reliability of the device it has been applied to.

Traditionally, the method used to inhibit grain growth was to prevent the diffusion of atoms by pinning secondary precipitates in grain boundaries $[13,14]$. However, since the types and sizes of the precipitates depend on the sort of metal or alloy, there has been a problem in that separate metal reaction studies have to be carried out for each variety of metal $[15,16]$.

In this study, we propose a method to obtain high-temperature stability, which can be applied to various metals, using carbon precipitate (graphene) and we then test it experimentally by using copper $(\mathrm{Cu})$. In particular, $\mathrm{Cu}$ thin films are widely used in the electronics industry because of their high thermal and electrical conductivity [17-19]. This conductivity is particularly influenced by the size and 
arrangement of grains, so close attention to graining is required [20,21]. It is known that the surface behaves similar to a liquid at a temperature close to its melting point of $1084{ }^{\circ} \mathrm{C}[22,23]$ at which $\mathrm{Cu}$ atoms actively move, and the grains grow in a crystalline orientation (described as the 111 orientation), in the most thermally stable direction $[24,25]$.

When graphene is grown on $\mathrm{Cu}$ foil by chemical vapor deposition (CVD), graphene is weakly bound to the $\mathrm{Cu}$ foil $(0.33 \mathrm{eV}$ per atom, the magnitude of the binding energy between graphene and transition metal atoms varies, depending on how many electrons are filled in the outermost orbitals of the metal atoms) [26,27]. Graphene synthesized onto the transition metal surface has been studied mainly in relation to chemical stability—such as corrosion and oxidation protection [28,29]—and has not been studied in terms of grain growth control, although the bulk graphene/ $\mathrm{Cu}$ composite materials have been studied for mechanical strength [30-32]. In this study, however, graphene was proposed for suppressing grain growth on metal in consideration of the excellent thermal conductivity and bonding energy associated with metal atoms. The repeated heat treatment of graphene-coated copper samples, synthesized at high temperatures, was investigated.

\section{Materials and Methods}

\subsection{Sample Preparation}

A commercial $25 \mu \mathrm{m}$ copper foil (item no. 13382, 99.8\% purity, Alfa Aesar, Ward Hill, MA, USA) was first immersed in $0.1 \mathrm{M}$ ammonium persulfate solution $\left(\left(\mathrm{NH}_{4}\right)_{2} \mathrm{~S}_{2} \mathrm{O}_{8}\right.$, item No. 248614, ACS reagent, 98.0\%, Sigma-Aldrich, St. Louis, MO, USA) for $1 \mathrm{~min}$ for cleaning and to etch oxide from the surface. Next, graphene growth was induced by loading the pre-etched $\mathrm{Cu}$ foil onto a quartz tube reaction chamber. Each Sample $(\mathrm{A}-\mathrm{C})$ was subjected to a CVD process three times, with and without methane $\left(\mathrm{CH}_{4}\right)$ flow.

The CVD process used went as follows:

- The pressure in the chamber was pumped down to 5 mTorr using a mechanical pump;

- Hydrogen $\left(\mathrm{H}_{2}\right)$ gas was injected into the chamber at $40 \mathrm{sccm}$, the temperature of the $\mathrm{Cu}$ foil then raised to $1000{ }^{\circ} \mathrm{C}$ over $60 \mathrm{~min}$;

- $\mathrm{CH}_{4}$ gas was injected into the chamber at $10 \mathrm{sccm}$ for $10 \mathrm{~min}$, for Samples A and B; for Sample C, there was no $\mathrm{CH}_{4}$ injection;

- Finally, the furnace was opened and rapidly cooled for about $20 \mathrm{~min}$ to $200{ }^{\circ} \mathrm{C}$.

This CVD process was repeated up to two more times to examine the thermal effect on grain growth on $\mathrm{Cu}$, as follows: Sample A had $\mathrm{CH}_{4}$ injection three times, Sample B had $\mathrm{CH}_{4}$ injection in the first process only, and Sample $\mathrm{C}$ did not have $\mathrm{CH}_{4}$ injection at any time.

\subsection{Analysis}

The Graphene/Cu samples were characterized by light microscopy (LM), Polarized light microscopy (PLM), X-ray diffraction (XRD), and Raman spectrometry. LM images were taken with a U-MSSP49 (Olympus, Tokyo, Japan) microscope, and, for PLM images, the samples were directly spin-coated with liquid crystal (4'-PENTYL-4-BIPHENYLCARBONITRILE, Sigma-Aldrich, item No. 328510, 98\%), then images were taken with the LM device and polarizer (U-AN369-3, Olympus). XRD analysis was performed with a Rigaku MiniFlex spectrometer ( $3 \mathrm{~kW}, \mathrm{Cu}-\mathrm{K} \alpha$, HD307172, Rigaku, Tokyo, Japan). Raman spectra were obtained with a LabRAM HR Evolution-Nicolet iS50 (Jobin Yvon, Horiba-Thermo, Kyoto, Japan) spectrometer, at $532 \mathrm{~nm}$ laser wavelength, $5 \mathrm{~mm}$ in diameter.

\section{Results and Discussion}

When the $\mathrm{Cu}$ foil reaches $1000{ }^{\circ} \mathrm{C}$, the growth temperature of graphene, the surface of the $\mathrm{Cu}$ foil behaves like a liquid ( $\mathrm{Cu}$ foil has a melting point of $\left.1084^{\circ} \mathrm{C}\right)$. At this temperature, the $\mathrm{Cu}$ atoms move 
freely to adopt a (111) direction, which is a thermodynamically stable direction resulting in retention of the (111) preferred orientation after rapid cooling.

However, when graphene is formed on the surface of $\mathrm{Cu}$ by precipitated carbon, it exhibits a different crystal orientation. The $\mathrm{Cu}(100)$ crystal plane, which can be nucleated easily on the graphene surface as it is kinetically favored over the (111) orientation, is formed at the bottom of graphene [25,33]. The (100) grains can suppress the bulk grain growth (111) orientation, as shown in Figure 1a. For an explanation of the sampling sequence, see also Figure $1 \mathrm{~b}$ and Table 1.

(a)
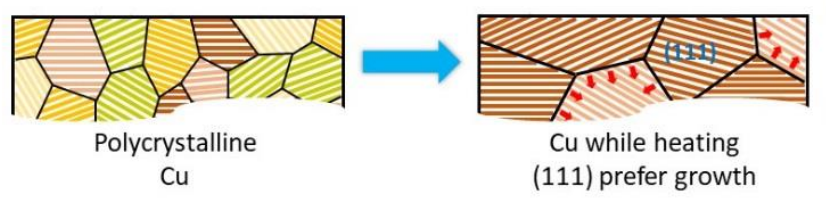

(111) prefer growth

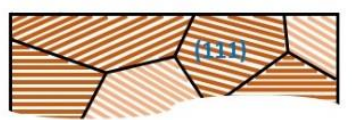

Cu without graphene after CVD

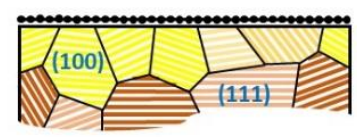

Cu with Graphene after CVD

(b)

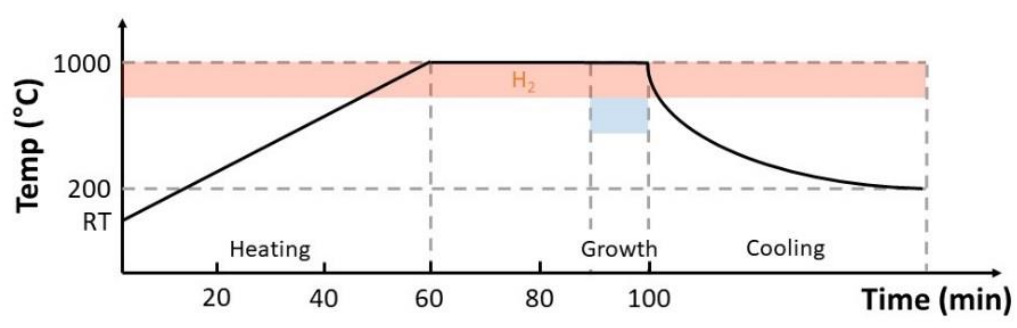

Figure 1. (a) Changes in $\mathrm{Cu}$ grains at the surface during the chemical vapor deposition (CVD) process; (b) CVD process conditions. At the time indicated in blue, $\mathrm{CH}_{4}$ was injected as indicated in Table 1.

Table 1. Sample treatment regarding $\mathrm{CH}_{4}$ injection.

\begin{tabular}{cccc}
\hline Injected Gas & $\mathbf{1}^{\text {st }}$ Cycle & $2^{\text {nd }}$ Cycle & $3^{\text {rd }}$ Cycle \\
\hline Sample A & $\mathrm{CH}_{4}$ & $\mathrm{CH}_{4}$ & $\mathrm{CH}_{4}$ \\
Sample B & $\mathrm{CH}_{4}$ & $\mathrm{X}$ & $\mathrm{X}$ \\
Sample C & $\mathrm{X}$ & $\mathrm{X}$ & $\mathrm{X}$ \\
\hline \multicolumn{4}{c}{ X means that no gas was injected. }
\end{tabular}

Each $\mathrm{Cu}$ foil sample exhibited growth of grains. However, the grain growth tendency on Samples $A$ and $B$, which were covered with graphene, was relatively less than that on Sample C (see Figure 2a showing the grains on $\mathrm{Cu}$, taken by $\mathrm{LM}$ ). Sample $\mathrm{C}$ exhibited a noticeably larger grain size when the CVD cycle was repeated. There was no significant change in grain size between each sample in the first CVD process. It is known that the CVD process for growing graphene made the $\mathrm{Cu}$ grain larger than annealing at the same temperature [34], but, in our experiment, there was an annealing time of $30 \mathrm{~min}$ before graphene growth. Since the grain growth effect of the $30 \mathrm{~min}$ annealing was greater than the effect of $10 \mathrm{~min}$ of graphene growth, each sample did not show a large difference in grain size after the first CVD process.

These results indicated that the graphene layer on the $\mathrm{Cu}$ surface suppressed grain growth on $\mathrm{Cu}$. As mentioned in Figure 1a, the increase in $\mathrm{Cu}(111)$ orientation has a direct effect on the grain growth, so it was necessary to confirm the ratio of the (111) peak, using XRD analysis. As shown in Figure $2 b$ and Table 2, repeating the CVD cycle did not gradually change the XRD peak. This is because Cu has a very large grain size distribution, and the penetration depth of the X-ray is deeper than the depth of the surface which is affected by graphene. The surface affected by graphene is atomically shallow, because graphene can only affect $\mathrm{Cu}$ atoms that are slightly bonded to it. 
(a)
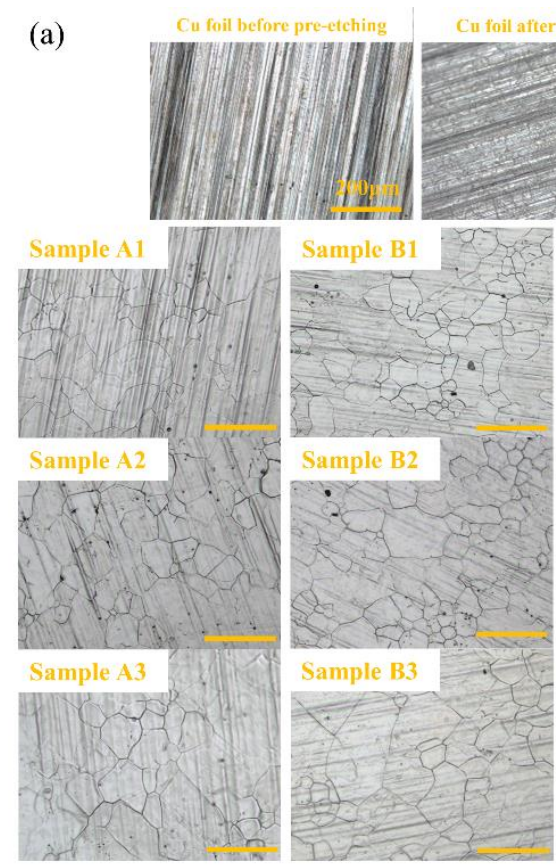

Cu foil after pre-etching
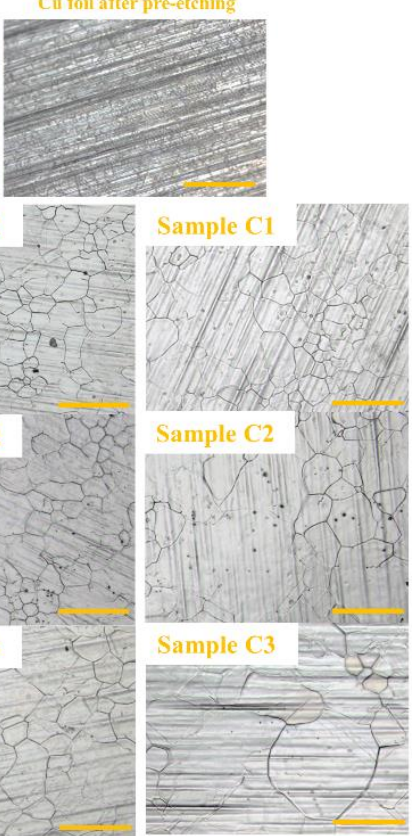

(b)
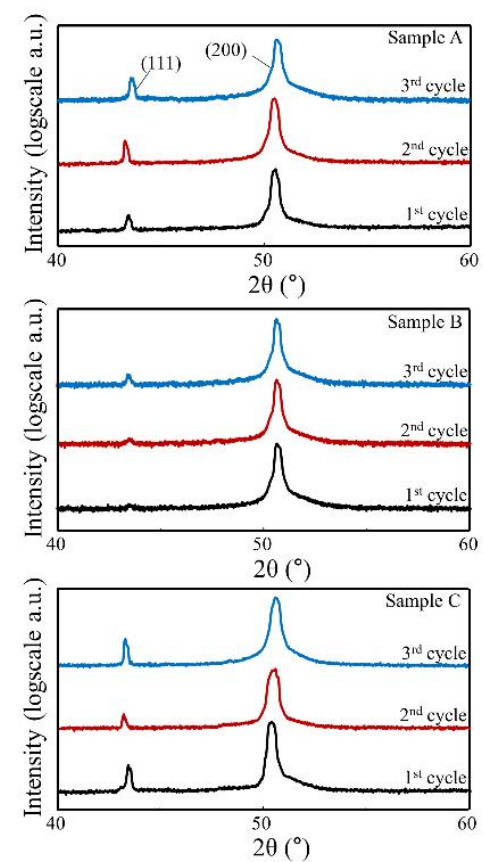

Figure 2. (a) Light microscopy (LM) images of Samples A-C, after each CVD cycle. The red shape on each LM image is the shape of the grain (b) X-ray diffraction (XRD) intensity ratios $I_{n} / I_{1}(n$ is the number of CVD cycle) for the (111) peak, for Samples A-C.

We calculated the average grain size on each $\mathrm{Cu}$ foil. As the images in Figure $3 \mathrm{a}, \mathrm{b}$ had lots of scratches, the computer program we used could not find the grain exactly. Therefore, we used the circle method from ASML E112 [35] (Incorrect ref order, 36 detected before 35. References should be cited in numerical order.) to distinguish the grain and scratches correctly. Equation (1) was used to calculate the grain size, by drawing a circle with a diameter of $200 \mu \mathrm{m}$ on an LM image magnified $\times 100$, as seen in Figure 3a,b.

$$
F_{m}=F_{k} /(0.67 n+z)
$$

In Equation (1), $F_{k}$ was the measured circle area on the LM image, $z$ was the number of grains completely within the test circle, and $n$ was the number of grains intercepted by the test circle. By assuming that the grains were circular, the average diameter of the grains was calculated using Equation (2).

$$
D=2 \sqrt{\frac{F_{m}}{\pi}}
$$

Figure $3 c$ shows the average grain area calculated with Equation (2). Because of the large grain size distribution of the $\mathrm{Cu}$ foil [36], 20 images per sample were taken and calculated to minimize the errors when selecting specific parts. Noting that the graphene was synthesized after annealing the $\mathrm{Cu}$ foil in the first CVD process, it was natural that there was no significant difference in grain size after the first cycle. From the second cycle, the grain size increase on the pure $\mathrm{Cu}$ foil with the CVD cycle was greater than that of the $\mathrm{Cu}$ foil with graphene. Furthermore, when the CVD cycle was repeated, the increase in the average grain size in the graphene-covered $\mathrm{Cu}$ foil became extremely small, and the grain area became constant. 
Table 2. Intensity ratio and full width at half maximum (FWHM) related to Figure $2 \mathrm{~b}$.

\begin{tabular}{cccc}
\hline FWHM & $\boldsymbol{I}_{(\mathbf{1 1 1})} / \mathbf{I}_{\mathbf{( 2 0 0 )}}$ Ratio & FWHM (200) & FWHM (111) \\
\hline Sample A1 & 0.0183 & 0.26 & 0.137 \\
Sample A2 & 0.0308 & 0.31 & 0.105 \\
Sample A3 & 0.0216 & 0.28 & 0.127 \\
Sample C1 & 0.0312 & 0.27 & 0.101 \\
Sample C2 & 0.0230 & 0.275 & 0.117 \\
Sample C3 & 0.0421 & 0.27 & 0.097 \\
\hline
\end{tabular}

(a)

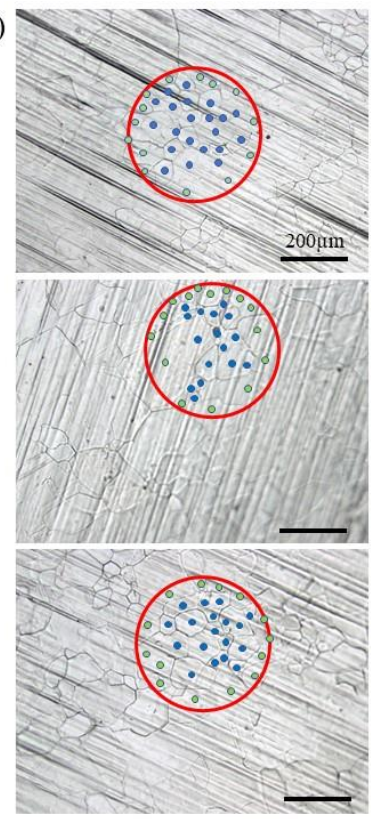

(b)

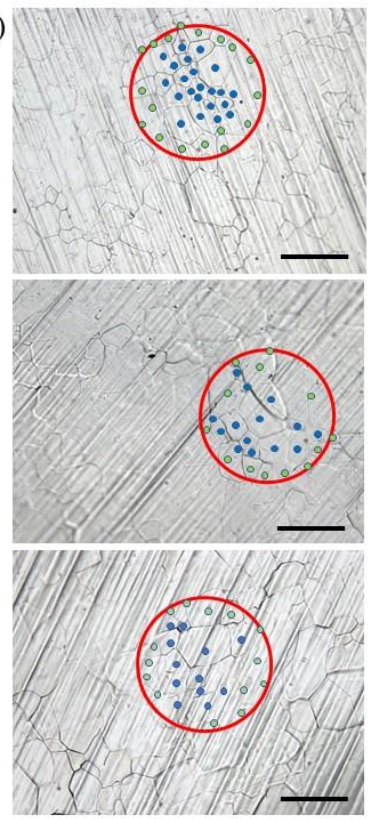

(c)

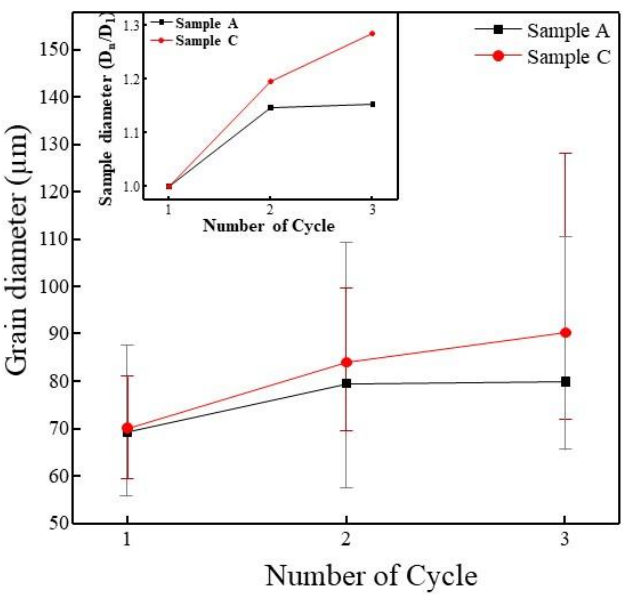

Figure 3. LM images of (a) Sample A, and (b) Sample C. A blue dot represents a grain in the red circle, and a green dot represents a grain that spans the red circle. (c) Calculated grain area after each CVD cycle.

Figure 4a shows the Raman shift of Samples A1, A2, B1, B2, and C1. In graphene, three peaks corresponding to the positions of approximately 1350,1600, and $2700 \mathrm{~cm}^{-1}$ appeared, which were called D peak, G peak, and 2D peak, respectively [37,38]. In Samples A1, A2, B1, and B2, there was a small D peak which indicated high quality and small defects of the graphene. The number of layers and quality of the graphene could be analyzed with the other two peaks. In all samples except Sample C, the intensity ratio of the two peaks $\left(I_{2 \mathrm{D}} / I_{\mathrm{G}}\right)$ was between 2 and 3 , which means that a single-layer graphene was synthesized. The intensity ratios of Samples A2 and B2 were not different from those of A1 and B1, meaning that repeated heating did not damage nor affect the number of graphene layers. Sample $\mathrm{C}$, which was not injected with $\mathrm{CH}_{4}$ during the CVD process, did not have any evidence of graphene. The graphene grain images obtained by repeating the CVD cycle once (A1) and three times (A3) were observed using PLM, and can be seen in Figure 4b [39]. The colors of A1 and A3 are different because of the different thicknesses of the liquid crystal. Sample C1 does not show any difference at various angles because the liquid crystal could not be aligned without graphene.

The grain size of the graphene did not change considerably. However, in Sample A3 in Figure 4b, we can see a rougher surface, which was caused by the movement of the $\mathrm{Cu}$ particles on the surface as a result of the repeated CVD cycles. 
(a)
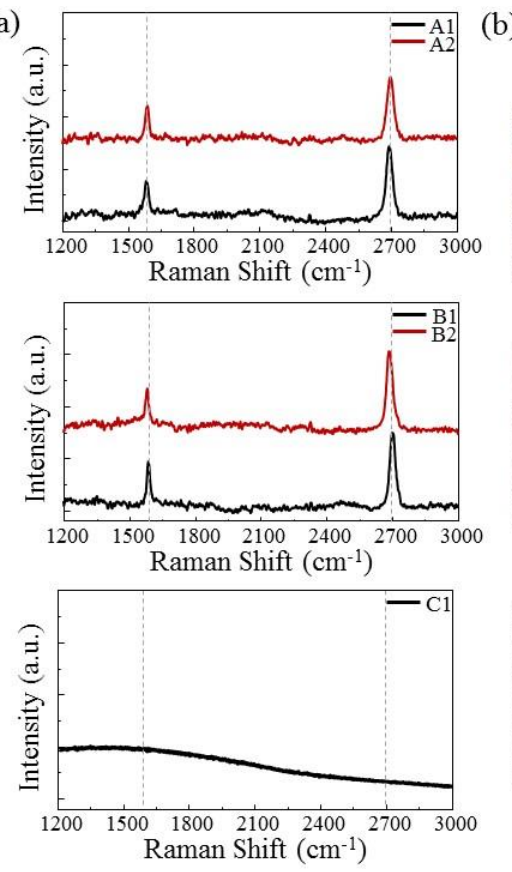

(b)

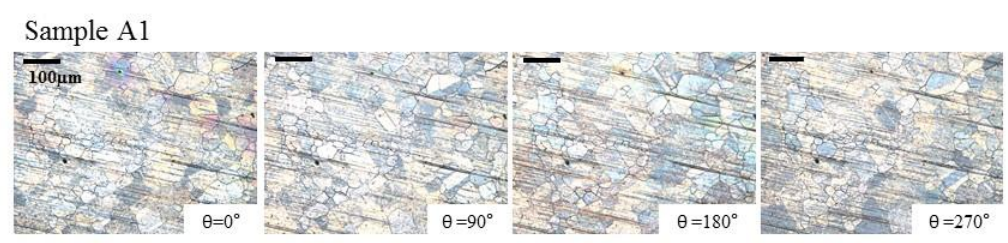

Sample A3
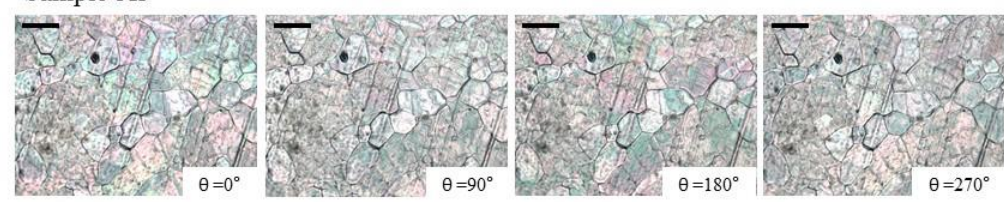

Sample C1
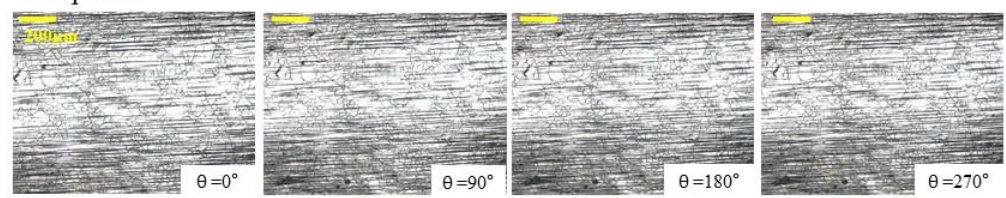

Figure 4. (a) Raman spectra of Samples A1, A2 (top), and B1, B2 (middle), and C1 (bottom). (b) Polarized Light Microscopy (PLM) images of Samples A1, A3, and C1.

We used the formula in Equation (3) below to calculate the theoretical grain size [40,41].

$$
D-D_{0}=(k t)^{1 / n}
$$

In Equation (3), $D$ was the grain size at time $t, D_{0}$ was the initial grain size, $n$ was the grain growth exponent, and $k$ was a temperature-dependent and grain boundary mobility relative constant, which was expressed with Arrhenius equation (Equation 4).

$$
k=k_{0} e\left(-E_{a} / \mathrm{RT}\right)
$$

In Equation (4), $k$ was the rate constant, $T$ was the absolute temperature, $k_{0}$ was the pre-exponential factor, $E_{a}$ was the activation energy, and $\mathrm{R}$ was the universal gas constant. We first determined the value of $k_{0}$ by substituting the grain size value from Samples C1-C3. The plot of $k$ for 1000/T of pure $\mathrm{Cu}$ using this value is shown in Figure 5a. The plot of graphene-covered $\mathrm{Cu}$ was drawn by applying the $\mathrm{C}-\mathrm{Cu}$ binding energy $(3182 \mathrm{~J} / \mathrm{mol})[26,27]$ and the activation energy of pure $\mathrm{Cu}$. With this plot, the $k$ value for $1000{ }^{\circ} \mathrm{C}$ was calculated as $0.05 \mu \mathrm{m}^{2} \mathrm{~s}^{-1}$.

In Figure $5 b$, the theoretical grain diameter was calculated by substituting the $k$ value. In the case of graphene- $\mathrm{Cu}$, it behaved like pure $\mathrm{Cu}$ at the first $\mathrm{CVD}$ cycle (0 to $2400 \mathrm{~s}$ ) because graphene was synthesized after $40 \mathrm{~min}$ of heating (30 min of annealing and $10 \mathrm{~min}$ of injecting $\mathrm{CH}_{4}$ ). Thus, the $\left(D-D_{0}\right)$ value was calculated with the activation energy of pure $\mathrm{Cu}$ for the first cycle and with the activation energy of graphene- $\mathrm{Cu}$ (which contains $\mathrm{C}-\mathrm{Cu}$ bonding energy) as well as the activation energy of pure $\mathrm{Cu}$ for the second and third cycles. After the first cycle, the theoretical value and the experimental value were significantly different for graphene- $\mathrm{Cu}$, while the values were almost in agreement in pure $\mathrm{Cu}$.

The reasons for this can be seen in Figure 5c. First, since graphene has high thermal conductivity [42,43], it takes away the heat from the $\mathrm{Cu}$ foil. Therefore, the $\mathrm{Cu}$ foil cannot receive the full thermal energy equivalent of $1000^{\circ} \mathrm{C}$; therefore, the corresponding grain growth does not occur. The second reason is that the $\mathrm{C}$ atoms are dissolved in the $\mathrm{Cu}$ foil at high temperatures. The remaining 
$\mathrm{C}$ atoms in the $\mathrm{Cu}$ foil suppress the potential shift of $\mathrm{Cu}$ dislocations and consequently interfere with grain growth $[44,45]$.

(a)

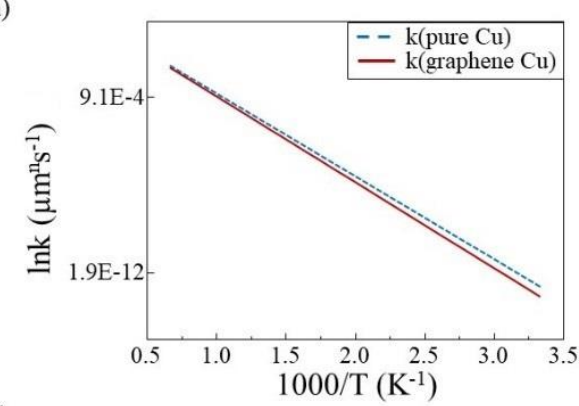

(b)

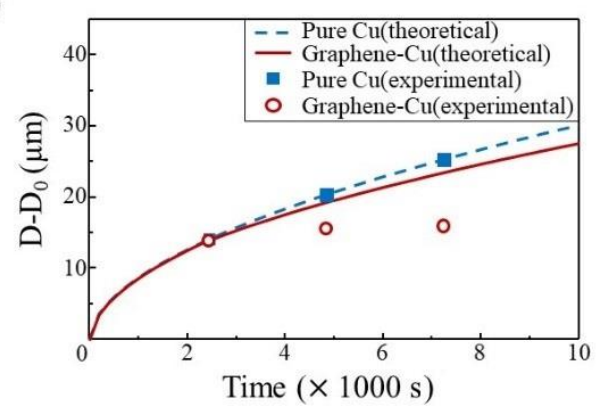

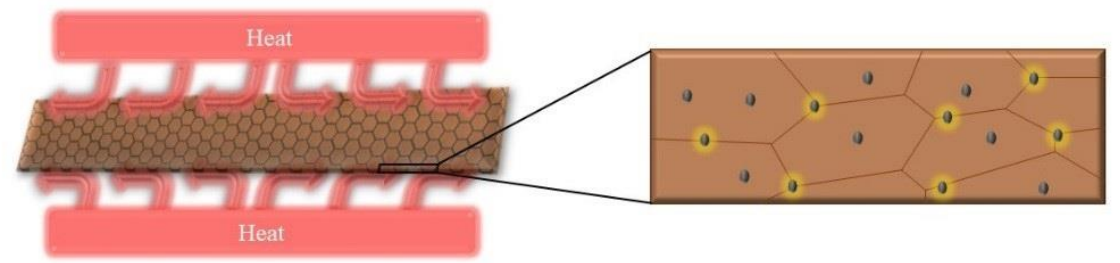

Figure 5. Pure $\mathrm{Cu}$ foil and graphene-covered $\mathrm{Cu}$ foil. (a) Plot of lnk against the annealing temperature $(1000 / T),(\mathbf{b})\left(D-D_{0}\right)$ against time, (c) schematic representation of the reasons of the gap between experimental and theoretical values for the graphene-covered $\mathrm{Cu}$ in $(\mathbf{b})$.

\section{Conclusions}

In conclusion, we investigated the effect of graphene on grain growth on $\mathrm{Cu}$ foil. A thermodynamic model was used to predict the extent of grain growth, on both graphene-covered $\mathrm{Cu}$ foil and pure $\mathrm{Cu}$ foil, and these predictions were then compared with actual experimental data.

It was seen that there was less grain growth on the surface of graphene-covered $\mathrm{Cu}$ than on pure $\mathrm{Cu}$. Grain growth occurred less than the predicted theoretical value on the surface of the graphene-covered $\mathrm{Cu}$, because of the high thermal conductivity of graphene and because $\mathrm{C}$ atoms dissolved in the $\mathrm{Cu}$.

It is expected that the application of graphene will suppress grain growth on transition metals used at high temperatures and that this technique will be easily applied to make materials more stable and less prone to thermal fatigue such as creep.

Author Contributions: Conceptualization, J.L. and H.K.Y.; Methodology, J.L. and H.S.; Validation, J.L. and H.S. and H.K.Y.; Formal Analysis, J.L.; Investigation, J.L. and H.S.; Data Curation, J.L. and H.S.; Writing-Original Draft Preparation, J.L.; Writing-Review \& Editing, J.L., H.S. H.K.Y. and J.-Y.C.; Visualization, J.L. and H.S.; Supervision, H.K.Y. and J.-Y.C.; Project Administration, J.L. and H.K.Y.; Funding Acquisition, H.K.Y.

Funding: This research received no external funding.

Acknowledgments: This work was supported by the Ajou University research fund.

Conflicts of Interest: The authors declare no conflict of interest.

\section{References}

1. Beaudoin, A.J.; Acharya, A.; Chen, S.R.; Korzekwa, D.A.; Stout, M.G. Consideration of grain-size effect and kinetics in the plastic deformation of metal polycrystals. Acta Mater. 2000, 48, 3409-3423. [CrossRef]

2. Saida, K.; Zhou, Y.; North, T.H. The influence of base metal grain size on isothermal solidification during transient liquid-phase brazing of nickel. J. Mater. Sci. 1993, 28, 6427-6432. [CrossRef]

3. Wu, P.D.; MacEwen, S.R.; Lloyd, D.J.; Neale, K.W. Effect of cube texture on sheet metal formability. Mater. Sci. Eng. A 2004, 364, 182-187. [CrossRef]

4. Stanford, N.; Barnett, M. Effect of composition on the texture and deformation behaviour of wrought $\mathrm{Mg}$ alloys. Scr. Mater. 2008, 58, 179-182. [CrossRef] 
5. Koike, J.; Wada, M.; Sanada, M.; Maruyama, K. Effects of crystallographic texture on stress-migration resistance in copper thin films. Appl. Phys. Lett. 2002, 81, 1017-1019. [CrossRef]

6. Hassan, A.M. The effects of ball- and roller-burnishing on the surface roughness and hardness of some non-ferrous metals. J. Mater. Process. Technol. 1997, 72, 385-391. [CrossRef]

7. Kim, S.H.; Na, S.W.; Lee, N.E.; Nam, Y.W.; Kim, Y.H. Effect of surface roughness on the adhesion properties of $\mathrm{Cu} / \mathrm{Cr}$ films on polyimide substrate treated by inductively coupled oxygen plasma. Surf. Coat. Technol. 2005, 200, 2072-2079. [CrossRef]

8. Ponsonnet, L.; Reybier, K.; Jaffrezic, N.; Comte, V.; Lagneau, C.; Lissac, M.; Martelet, C. Relationship between surface properties (roughness, wettability) of titanium and titanium alloys and cell behavior. Mater. Sci. Eng. C 2003, 23, 551-560. [CrossRef]

9. Harper, J.M.E.; Cabral Jr, C.; Andricacos, P.C.; Gignac, L.; Noyan, I.C.; Rodbell, K.P.; Hu, C.K. Mechanisms for microstructure evolution in electroplated copper thin films near room temperature. J. Appl. Phys. 1999, 86, 2516-2525. [CrossRef]

10. Koo, J.B.; Yoon, D.Y. Abnormal grain growth in bulk Cu-The dependence on initial grain size and annealing temperature. Metall. Mater. Trans. A 2001, 32, 1911-1926. [CrossRef]

11. Weihnacht, V.; Brückner, W. Abnormal grain growth in $\{111\}$ textured $\mathrm{Cu}$ thin films. Thin Solid Films 2002, 418, 136-144. [CrossRef]

12. Huang, J.S.; Zhang, J.; Cuevas, A.; Tu, K.N. Recrystallization and grain growth in bulk $\mathrm{Cu}$ and $\mathrm{Cu}(\mathrm{Sn})$ alloy. Mater. Chem. Phys. 1997, 49, 33-41. [CrossRef]

13. Hibbard, G.D.; McCrea, J.L.; Palumbo, G.; Aust, K.T.; Erb, U. An initial analysis of mechanisms leading to late stage abnormal grain growth in nanocrystalline Ni. Scr. Mater. 2002, 47, 83-87. [CrossRef]

14. Afshar, A.; Simchi, A. Abnormal grain growth in alumina dispersion-strengthened copper produced by an internal oxidation process. Scr. Mater. 2008, 58, 966-969. [CrossRef]

15. Barmak, K.; Gungor, A.; Cabral, C.; Harper, J.M.E. Annealing behavior of Cu and dillute Cu-alloy films: Precipitation, grain growth, and resistivity. J. Appl. Phys. 2003, 94, 1605-1616. [CrossRef]

16. Zheng, Y.; Li, X.; Cheng, X.; Li, Z.; Liu, Y.; Dong, C. Enhanced thermal stability of Cu alloy films by strong interaction between Ni and $\mathrm{Zr}$ (or Fe). J. Phys. D Appl. Phys. 2018, 51, 135304. [CrossRef]

17. Kang, M.G.; Park, H.J.; Ahn, S.H.; Guo, L.J. Transparent Cu nanowire mesh electrode on flexible substrates fabricated by transfer printing and its application in organic solar cells. Sol. Energy Mater. Sol. Cells 2010, 94, 1179-1184. [CrossRef]

18. Zhuang, Z.; Su, X.; Yuan, H.; Sun, Q.; Xiao, D.; Choi, M.M. An improved sensitivity non-enzymatic glucose sensor based on a $\mathrm{CuO}$ nanowire modified Cu electrode. Analyst 2008, 133, 126-132. [CrossRef] [PubMed]

19. Taberna, P.L.; Mitra, S.; Poizot, P.; Simon, P.; Tarascon, J.M. High rate capabilities $\mathrm{Fe}_{3} \mathrm{O}_{4}$-based $\mathrm{Cu}$ nano-architectured electrodes for lithium-ion battery applications. Nat. Mater. 2006, 5, 567-573. [CrossRef] [PubMed]

20. Rossnagel, S.M.; Kuan, T.S. Alteration of $\mathrm{Cu}$ conductivity in the size effect regime. J. Vac. Sci. Technol. B 2004, 22, 240-247. [CrossRef]

21. Takata, N.; Lee, S.H.; Tsuji, N. Ultrafine grained copper alloy sheets having both high strength and high electric conductivity. Mater. Lett. 2009, 63, 1757-1760. [CrossRef]

22. Hsieh, Y.P.; Chen, D.R.; Chiang, W.Y.; Chen, K.J.; Hofmann, M. Recrystallization of copper at a solid interface for improved CVD graphene growth. RSC Adv. 2017, 7, 3736-3740. [CrossRef]

23. Li, X.; Cai, W.; An, J.; Kim, S.; Nah, J.; Yang, D.; Piner, R.; Velamakanni, A.; Jung, I.; Tutuc, E.; et al. Large-area synthesis of high-quality and uniform graphene films on copper foils. Science 2009, 324, 1312-1314. [CrossRef] [PubMed]

24. Zhao, L.; Rim, K.T.; Zhou, H.; He, R.; Heinz, T.F.; Pinczuk, A.; Flynn, G.W.; Pasupathy, A.N. Influence of copper crystal surface on the CVD growth of alrge area monolayer graphene. Solid State Commun. 2011, 151, 509-513. [CrossRef]

25. Lu, A.Y.; Wei, S.Y.; Wu, C.Y.; Hernandez, Y.; Chen, T.Y.; Liu, T.H.; Pao, C.W.; Chen, F.R.; Li, L.J.; Juang, Z.Y. Decoupling of CVD graphene by controlled oxidation of recrystallized Cu. RSC Adv. 2012, 2, 3008-3013. [CrossRef]

26. Giovannetti, G.A.K.P.A.; Khomyakov, P.A.; Brocks, G.; Karpan, V.V.; van den Brink, J.; Kelly, P.J. Doping graphene with metal contacts. Phys. Rev. Lett. 2008, 101, 026803. [CrossRef] [PubMed] 
27. Vanin, M.; Mortensen, J.J.; Kelkkanen, A.K.; Garcia-Lastra, J.M.; Thygesen, K.S.; Jacobsen, K.W. Graphene on metals: A van der Waals density functional study. Phys. Rev. B 2010, 81, 081408. [CrossRef]

28. Prasai, D.; Tuberquia, J.C.; Harl, R.R.; Jennings, G.K.; Bolotin, K.I. Graphene: Corrosion-inhibiting coating. ACS Nano 2012, 6, 1102-1108. [CrossRef] [PubMed]

29. Chen, S.; Brown, L.; Levendorf, M.; Cai, W.; Ju, S.Y.; Edgeworth, J.; Li, X.; Magnuson, C.W.; Velamakanni, A.; Piner, R.D.; et al. Oxidation resistance of graphene-coated $\mathrm{Cu}$ and $\mathrm{Cu} / \mathrm{Ni}$ alloy. ACS Nano 2011, 5, 1321-1327. [CrossRef] [PubMed]

30. Si, X.; Li, M.; Chen, F.; Eklund, P.; Xue, J.; Huang, F.; Du, S.; Huang, Q. Effect of carbide interlayers on the microstructure and properties of graphene-nanoplatelet-reinforced copper matrix composites. Mat. Sci. Eng. A 2017, 708, 311-318. [CrossRef]

31. Chu, K.; Wang, F.; Wang, X.H.; Huang, D.J. Anisotropic mechanical properties of graphene/copper composites with aligned graphene. Mat. Sci. Eng. A 2018, 713, 269-277. [CrossRef]

32. Wang, X.; Wang, X.; Liu, M.; Crimp, M.A.; Wang, Y.; Qu, Z. Anisotropic thermal expansion coefficient of multilayer graphene reinforced copper matrix composites. J. Alloy. Compd. 2018, 755, 114-122. [CrossRef]

33. Wofford, J.M.; Nie, S.; McCarty, K.F.; Bartelt, N.C.; Dubon, O.D. Graphene island on Cu foils: The interplay between shape, orientation, and defects. Nano Lett. 2010, 10, 4890-4896. [CrossRef] [PubMed]

34. Goli, P.; Ning, H.; Li, X.; Lu, C.Y.; Novoselov, K.S.; Balandin, A.A. Thermal properties of graphene-copper-graphene heterogeneous films. Nano Lett. 2014, 14, 1497-1503. [CrossRef] [PubMed]

35. Zielinski, E.M.; Vinci, R.P.; Bravman, J.C. Effects of barrier layer and annealing on abnormal grain growth in copper thin films. J. Appl. Phys. 1994, 76, 4516-4523. [CrossRef]

36. ASTM E112-13 Standard Test Methods for Determining Average Grain Size; ASTM International: West Conshohocken, PA, USA, 2013.

37. Malard, L.M.; Pimenta, M.A.A.; Dresselhaus, G.; Dresselhaus, M.S. Raman spectroscopy in graphene. Phys. Rep. 2009, 473, 51-87. [CrossRef]

38. Park, J.S.; Reina, A.; Saito, R.; Kong, J.; Dresselhaus, G.; Dresselhaus, M.S. G' band Raman spectra of single, double and triple layer graphene. Carbon 2009, 47, 1303-1310. [CrossRef]

39. Kim, D.W.; Kim, Y.H.; Jeong, H.S.; Jung, H.T. Direct visualization of large-area graphene domains and boundaries by optical birefringency. Nat. Nanotechnol. 2012, 7, 29-34. [CrossRef] [PubMed]

40. Simoes, S.; Calinas, R.; Vieira, M.T.; Vieira, M.F.; Ferreira, P.J. In situ TEM study of grain growth in nanocrystalline copper thin films. Nanotechnology 2010, 21, 145701. [CrossRef] [PubMed]

41. Atkinson, H.V. Overview no.65: Theories of normal grain growth in pure single phase systems. Acta Metall. 1988, 36, 469-491. [CrossRef]

42. Balandin, A.A.; Ghosh, S.; Bao, W.; Calizo, I.; Teweldebrhan, D.; Miao, F.; Lau, C.N. Superior thermal conductivity of single-layer graphene. Nano Lett. 2008, 8, 902-907. [CrossRef] [PubMed]

43. Ghosh, D.; Calizo, I.; Teweldebrhan, D.; Pokatilov, E.P.; Nika, D.L.; Balandin, A.A.; Bao, W.; Miao, F.; Lau, C.N. Extremely high thermal conductivity of graphene: Prospects for thermal management applications in nanoelectronic circuits. Appl. Phys. Lett. 2008, 92, 151911. [CrossRef]

44. Aaron, H.B.; Aaronson, H.I. Growth of grain boundary precipitates in Al-4\% Cu by interfacial diffusion. Acta Metall. 1968, 16, 789-798. [CrossRef]

45. Speight, M.V. Growth kinetics of grain-boundary precipitates. Acta Metall. 1968, 16, 133-135. [CrossRef]

(C) 2018 by the authors. Licensee MDPI, Basel, Switzerland. This article is an open access article distributed under the terms and conditions of the Creative Commons Attribution (CC BY) license (http://creativecommons.org/licenses/by/4.0/). 